\section{As artes do visível segundo Derrida}

Derrida, Jacques. Pensar em não ver: escritos sobre as artes do visível (1979-2004). Organização Ginette Michaud, Joana Masó, Javier Bassas. Trad. Marcelo Jacques de Moraes. Florianópolis: Ed. da UFSC, 2012. 480 páginas.

\author{
Luciana Abreu Jardim ${ }^{*}$ \\ Fundação Universidade do Rio Grande
}

Reler Jacques Derrida, no conjunto de entrevistas, conferências e outros textos fragmentados sobre aspectos das artes visuais, em Pensar em não ver, é um convite aprazível para o acesso e possível desvendamento de obras teóricas do filósofo da desconstrução. Em Da gramatologia (1967), Derrida abala o primado da voz, o que instaura uma série de conceitos relacionados à noção différance, de modo a chamar a atenção para a consolidação e posterior questionamento da metafísica da presença. Em $A$ voz e o fenômeno (1967), o filósofo apresenta argumentos que, relacionados à construção da afetividade em função da presença no tempo, fundamentam a constituição histórica do primado da voz. Estamos diante de obras teóricas que requerem, por parte dos leitores, algum trânsito em textos filosóficos ou, pelo menos, o contato prévio com o tema da temporalidade, cuja herança o filósofo resgatará de teses de Husserl e de Heidegger.

Ao reunir diferentes textos relacionados às artes visuais (pintura, desenho, cinema, teatro), o efeito produzido pelos organizadores de Pensar em não ver é o de retorno não apenas de questões seminais da desconstrução, que foram discutidas sobretudo nas obras teóricas supracitadas, mas também do tema da visibilidade, no tocante às obras de arte, que está problematizado em obras como $A$ verdade em pintura (1978); Memórias de cego: o autorretrato e outras ruínas (1990) - para citar apenas alguns exemplos notáveis.

\footnotetext{
Luciana Abreu Jardim holds a Master (2003) and a Ph.D. Literary Theory (2008), both from Pontifícia Universidade Católica do Rio Grande do Sul. Since 2013 she works at the Postgraduate Program of Literature, Fundação Universidade do Rio Grande, as a researcher and a teacher. She is currently developing a research project on motherhood and literature, focusing on Julia Kristeva’s theory and Brazilian women writers E-mail: lucianajardim.1@ hotmail.com
}

$\mathrm{Na}$ entrevista de abertura a Peter Brunette e David Wills, intitulada "As artes espaciais" (de 1990), o filósofo marca uma importante distinção entre espacialidade e visualidade, que será a base para a apreensão do que escapa ao par antitético visível/invisível, uma vez que, para ele, o invisível "não é apenas o contrário da visão" (46). Nessa medida, há algo que foge ao olhar quando se pensa no espaço. Ao ser perguntado sobre a (des)construção de seus textos, o filósofo dirá que a sua busca é pelo "tom", isto é, uma voz que não é discursiva. Curiosamente, essa voz nem sempre aparece gramaticalmente marcada no texto. Aí surge a espacialização da escrita derridiana, que reside no fato de esse deslocamento ser de fundo invisível, gerando um mal-estar aos que o leem: “[ ...] o que realmente chateia é essa espacialização, o fato de que não se saber mais com quem se está lidando, quem assina, como tudo se reúne [se rassemble]; é isso que os perturba, que os amendronta" (42). Esse estranhamento produzido pela "diferencialidade do tom" possibilita estender as artes visuais na ordem do espaçamento e, por conseguinte, do invisível.

Na conferência "Com o desígnio, o desenho", de 1991, a referida invisibilidade se revela através de um dado biográfico do autor.

[...] há desde sempre o sentimento de nunca ter sido capaz não apenas de desenhar (eu nunca consegui desenhar sequer a coisa mais elementar), mas eu nunca pude sequer olhar um desenho. Os senhores compreendem que alguém que tem o sentimento, a estranha certeza de nunca ter podido desenhar no sentido realmente mais elementar, mais primário do termo, e que sente até mesmo que não pode olhar um desenho, que não pode ver um desenho, perceber um desenho, imaginem o que acontece quando o Louvre o convida para organizar uma exposição de desenhos. (180)

A confissão de um fracasso artístico transforma-se em experiência teórica. Na conferência "Pensar em não ver", que dá título ao volume em questão, o conceito de experiência [Erfahrung] é retomado pelo filósofo e em seguida é associado ao processo de "não ver". No que se refere à noção de experiência, Derrida foge de um vínculo com a metafísica da presença, que privilegiaria a suposta precisão do presente e fortaleceria assim o logocentrismo e também o primado da voz. Segundo o filósofo, a experiência é como uma viagem: "o que quer dizer experimentar rumo a, através da ou desde a vinda do outro na sua heterogeneidade mais imprevisível; tratase da viagem não programável, da viagem cuja cartografia 
não é desenhável, de uma viagem sem design, de uma viagem sem desígnio, sem meta e sem horizonte" (80). Esse deixar-se levar pelo desconhecido, segundo Derrida, não pode ser localizado nas categorias de objetividade e de subjetividade. Na sequência do argumento, essa definição de experiência é associada à (in)visibilidade característica do desenho. Note-se que, ao longo de suas obras, ele destaca e questiona a importância do sentido de visão para filósofos de distintos momentos históricos - fato que promoverá a desconstrução do primado visual e sua ambição de objetividade. No texto da conferência "Pensar em não ver", Derrida retoma o eidos platônico, demonstrando que o abalo das categorias de objetividade e de subjetividade se constrói como uma forma, ou para nos aproximarmos das artes visuais, como um desenho. Ademais, segundo a leitura de Derrida, o eidos precisa ser iluminado por uma luz solar. Todavia, esse sol, por ser ofuscante, não se mostra à visibilidade. Esse estranho paradoxo de herança platônica serve para entrarmos em contato com a também paradoxal experiência de invisibilidade que é desencadeada quando somos tocados por um desenho ou uma pintura capazes de alcançar essas zonas de luminosidade cegante: "Os desenhistas, os pintores não dão a ver 'alguma coisa', sobretudo os grandes; eles dão a ver a visibilidade, o que é uma coisa absolutamente irredutível ao visível, que permanece invisível" (82). A essa experiência, que embaralha e abala o par opositivo visível/invisível, Derrida dá o nome de "enceguecimento".

O contato com as pinturas de Salvatore Puglia, no texto "Salvar os fenômenos. Para Salvatore Puglia" (de 1995), o leva a refletir sobre a atividade da pintura na sua relação com o pensamento. Algo do eidos platônico volta ao debate ao longo dessas reflexões, especialmente quando Derrida analisa o trabalho Ashbox, título de uma das aquarelas do pintor italiano. A experiência artística de Puglia fez com que ele atravessasse vários idiomas: o grego, o alemão, $\mathrm{o}$ francês e o inglês. Inicialmente, Derrida lança, sob a forma de pergunta, a possível relação entre pintura e tradução. Subjaz a essa indagação a possibilidade de se pensar sobre o próprio da pintura. "Perguntamo-nos se uma pintura pode um dia se despojar das letras, ou mesmo do vocábulo" (212). O interesse pela palavra que se inscreve na pintura também norteia o contato do filósofo com o trabalho do pintor Valerio Adami. Na entrevista intitulada "Êxtase, crise. Entrevista com Roger Lesgards e Valerio Adami" (de 2001), o pintor, na tentativa de explicar o seu processo de criação, que é muito semelhante à noção de experiência outrora referida por Derrida, sustenta que trabalha movido por uma memória instintiva. De acordo com Adami: "A mão se move porque consigo realmente me esvaziar de tudo, deixando a ela a liberdade" (239). Todavia, Derrida fica seduzido (é a expressão do filósofo) pelas palavras na pintura de Adami. E, quando imaginamos que o filósofo estabelecerá vínculos com a noção de enceguecimento, ele elege um outro fio interpretativo: "por mais absoluto desenhista que ele seja, e pintor, apesar de tudo, ele acolhe no espaço do que assina inúmeras artes, a literatura em especial - encontramos frases, textos, personagens da literatura, a família dos escritores. Joyce ou Benjamin, por exemplo" (239). Seria interessante, como sugestão para futuras pesquisas, voltarmos à recorrente tensão entre palavra e imagem nas diversas obras derridianas. Antonin Artaud é outra referência cujo trabalho visual repercute sobre o conjunto da obra de Derrida. No fragmento de conferência de 2002, de "Os debaixos da pintura, da escrita e do desenho: suporte, substância, sujeito, sequaz e suplício", Artaud, que é mencionado em Da gramatologia, além de ter importantes aspectos de sua obra analisados em Escritura e diferença (1967), volta à cena, ao ser referido na obra cujo tema gira em torno da palavra subjétil (cf. Enlouquecer o subjétil) - palavra que é recuperada por ele mesmo. Esse artista, que circula sob o epíteto de maldito, viabilizou ao filósofo um encontro com um pensamento da margem, do suporte, da moldura. Pela perspectiva de tom poético acerca da pintura, o texto "Pregnâncias. Sobre quatro aguadas de Colette Deblé”, a temática do subjétil volta sob a inspeção da mulher-suporte, desembocando no corpo feminino, na busca por uma representação do feminino na pintura e, por conseguinte, na história da pintura. A técnica de Deblé, aguada (lavis), longe de promover a estabilidade da representação do feminino na pintura, contribui para refletirmos sobre essa ausência.

Os artigos destinados às áreas do cinema, da fotografia e do teatro abordam a "invisibilidade" não pelo viés do enceguecimento, mas pela noção de espectralidade. Nessa medida, os organizadores incluem um texto sobre Marx, que fará alusão à obra Espectros de Marx (1993), na qual esse conceito se mostra longamente desenvolvido. Em "Marx é alguém" (de 1997), Derrida recupera o conceito de espectro por meio do teatro. Inicialmente, define espectro como "algo entre a vida e a morte, nem vivo nem morto" (426). E o teatro seria o local ideal de manifestação dos espectros, dado que nesse ambiente não se distingue o visível do invisível. Em outro texto, surge a seguinte questão: estaria no teatro, conforme "O Sacrifício" (de 1991/2006), sobretudo na tragédia grega, a possibilidade de representação do sacrifício? Ao expor uma tese de 
Daniel Mesguich, apresentada em O eterno efêmero, Derrida se interessa pela afirmação de que "haveria uma enorme diferença entre o sacrifício e o teatro" (403). Ao recuperar essa tese de cunho desconstrutivista, Derrida, ao mesmo tempo, retira da filosofia a dissociação do elemento trágico - o fato de ter se desenvolvido em virtude do "fim de certa tragédia" (402) - e abre espaço para repensarmos a filosofia sob uma estrutura trágica ou sacrificial. Esse gesto é apenas esboçado por ele nesse texto, uma vez que afirma não poder se "engajar nesse imenso debate" (402). Em contrapartida, algo que está na contracorrente da história do pensamento filosófico surge quando ele promove a inversão do espaço dado ao sacrifício no tocante às áreas do teatro e da filosofia. Esse elemento deixado de lado retorna à cena para abalar a tradição filosófica. Assim, o percurso pelo sacrifício estabelece acesso ao conceito de espectro, tornando-se um tema filosófico cuja herança passa pela (in)visibilidade dessa experiência arcaica.

Há também espectralidade nas telas do cinema, do vídeo e da lente fotográfica, ainda que não disponham da mesma intensidade sacrificial cuja herança está no teatro. Curiosamente, o filósofo faz distinção entre o pensamento filosófico e as ideias que surgem nos trabalhos dos diretores de cinema e dos artistas visuais. Mesmo sem o envolvimento conceitual necessário para os filósofos, os artistas são capazes de produzir sentido ou, em outras palavras, pensamento, porque estão envolvidos em processos de memória e tradição da obra. Esses artistas visuais, especialmente os da área do cinema, permitem ao filósofo reflexões que questionam e até mesmo excedem o âmbito da filosofia: “[...] é necessário dizer que há pensamento, alguma coisa que produz sentido, sem pertencer à ordem do sentido, que excede o discurso filosófico e questiona a filosofia, que potencialmente contém um questionamento da filosofia, que vai além da filosofia" (46). Se esse questionamento acontece, ou seja, algo produzido por artistas escapa ao controle da filosofia, deveríamos buscar na obra derridiana as diversas leituras da espectralidade, pois é o efeito desse elemento perturbador que instaura a possibilidade de outros sentidos, os quais não são controlados pela tradição filosófica.

Em "O cinema e seus fantasmas. Entrevista com Antoine de Baecque e Thierry Jousse" (1998 e 2000), Derrida comenta ter frequentado as salas de cinema de Argel ainda muito jovem. Experiência que para ele significava o "afastamento da família" (373), o cinema não lhe produzia rastros, memórias ou qualquer vínculo com atividades de trabalho. Nessa perspectiva de negações, o filósofo associa o cinema à espectralidade na sua relação com a psicanálise (377), especialmente no tocante ao Umheimlich freudiano. Sobre a exibição do filme D'ailleurs, Derrida, de (1999), escrito por Safaa Fathy, o estranhamento familiar se exemplifica através de uma série de recursos de corte entre o que é mostrado e o que é falado: "Não estou ali onde falo, ali onde isso fala, estou alhures e há uma fala mais velha do que eu" (115). Os recursos técnicos que viabilizam uma fala dissociada do corpo, outra forma de acesso à noção de différance, levam também ao entredito, que é enaltecido pelo filósofo pela expressão sentimento de segredo.

Em "A dança dos fantasmas. Entrevista com Mark Lewis e Andrew Paine" (de 1987), Derrida comenta a respeito de sua atuação em Ghost dance, um filme no qual afirma ter atuado apenas como ator - novamente os espectros na formação da cena: "Eu estava lá, como ator, fazendo o papel de um professor de filosofia a quem uma estudante de antropologia vinha perguntar se ele acreditava em fantasmas" (361). E como ator, numa das últimas cenas escritas de sua (bio)bliografia, um texto sobre a condição espectral do próprio pensador é habilmente escolhido pelos organizadores do volume para homenageá-lo. Convidado a escrever para a seção "Pourquoi vous prenez-vous", da Quinzaine Littéraire, no ano que culminaria na sua morte, o filósofo escolhe três palavras para responder à questão proposta pelos amigos. Entre as palavras escolhidas, aquela que melhor combina com a reflexão sobre a (in) visibilidade, permitindo o aprofundamento confessional do conceito de espectro, está resumida no léxico sursis:

eu não apenas já teria "passado", eu pertenceria a uma geração de "mortos"; mas sou de um ceticismo absoluto quanto à sobrevivência, por mais curta que seja, daquilo que deixarei na minha morte. Inversamente, alguns sinais me fazem crer, e no mesmo momento, que mal comecei a escrever, e que, exceto por raras exceções, mal começaram a me ler. (438)

Eis um convite para reler Jacques Derrida, a partir de Pensar em não ver, seguindo gestos que condensam elucidativamente vários aspectos teóricos e confessionais de um pensador cujos flagrantes visuais, para além da metafísica da presença, levam a zonas de experiências a serem escritas.

Recebido em: 21/06/2014 Aceito em: 18/08/2014 
